\title{
QUALITY OF LIFE INDICATORS AND PROGRAM EVALUATION
}

\author{
STEPHEN B. WITHEY \\ University of Michigan
}

\begin{abstract}
Social indicators and program evaluation research have much in common. Quality of life work specifically raises the question of objective versus subjective variables, aggregate data versus distributional and individual issues, and the reference standards used in judgment and evaluation decisions. This article presents perspectives on these issues from the orientation of quality of life research and proposes that these approaches have relevance for program evaluation work.
\end{abstract}

Social indicators research is about the same age as evaluation research. Both have the same disciplinary origins in economics, sociology and social psychology. Both areas of activity are engaged in collecting statistics of direct normative interest, the assessment of social change or stability and the detection of factors effective in achieving social and policy goals. Historically, evaluation research has focused on specific programmatic efforts while social indicator research has tried to assess a wider mix of societal variables and contexts. Both, however, are interested in the complex structure of networks of interacting variables and the effects of directed policy and social programs in the flow of less purposeful social trends. Both expect the dissemination and understanding of their results to be followed by some cognitive shift with behavioral or policy consequences. Thus one can look for considerable overlap in the problems and issues arising in each area of research.

\section{OBJECTIVE VERSUS SUBJECTIVE MEASURES}

Certainly one of the major controversies in social in dicator studies is the role of objective versus subjective variables. Disciplines and people within them differ in their emphasis on "hard" data. There are differences too in the conceptualization of well-being and welfare and measurement problems are always with us. Formulators of the social indicators movement (Bauer, 1966; Olson, 1969; Sheldon \& Moore, 1968; and others) were initially concerned with the inadequacies of social data and the resulting lack of insights into social functioning. Part of the lack of understanding was associated with the realization that in spite of improvement in physical well-being the quality of life had not uniformly improved. This occurred because of a new mix of objective factors and a shift in standards for judgment as expressed in the ideal of a revolution in aspirations and expectations. At any rate the social indicators effort rapidly led to research in the quality of life and this work partly emphasized subjective judgments and evaluations.

Economists have been interested in aggregate output. The GNP is a product that itself engenders arguments as to the adequacy of its assessment of societal wellbeing. These aggregate measures dodge any distributional issues about differences in well-being within a society. This stems from the refusal of economists, in general, to make interpersonal comparisons of utility or well-being. From this posture the emphasis on aggregate production or consumption is understandable. The GNP-type "goods" are presumably instrumental in securing, in turn, actual "objects" of utility; but in tracking the productive process it is not teacher salaries 
but achicved pupil skills that are the product; it is not money for hospitals but health that constitutes welfare; it is not money spent on construction but the quality of the neighborhood that is well-being. Carrying the argument further, the objective products of production or of a program are hopefully satisfaction, improvement and well-being. It is this pressure to account for social efforts in terms of their final and intended product that leads some to wrestle with the conceptual, measurement and interpretation problems associated with the assessment of subjective states of well-being now collectively termed the quality of life.

Policies and programs create a sequence of effects or products. Although one can stop with assessing program goals of reduced days in hospital, fewer arrests, better scores on tests, etc., there is a sense in which many of these programmatic goals also end up in subjective support, appreciătion and understanding. If not, the program may be in trouble.

A classic example of the problems of objective and subjective factors, aggregate and individual characteristics and different reference standards is of- fered by Easterlin (1973). He found that rising levels of income do not produce increases in the average subjective estimate of welfare. From studies in 19 countries he reports that "in all societies, more money for the individual typically means more individual happiness. However, raising the incomes of all does not increase the happiness of all. Individuals assess their material well-being, not in terms of the absolute amount of goods they have, but relative to a social norm of what goods they ought to have. Rainwater (1974) documented a reference norm by citing 18 studies between 1946 and 1969 in which the "smallest amount of money a family of four needs to get along" increased by a factor of 1.36 between 1954 and 1969 using constant 1971 dollars. Duncan (1975) replicates this finding reporting that "there was no change in the distribution of satisfaction with the standard of living among Detroit wives between 1955 and 1971, although currentdollar income increased by forty percent. Crosssectional variation in satisfaction is, however, related to income and, in particular, to relative position in the income distribution."

\section{WHAT DO WE KNOW ABOUT SUBJECTIVE MEASURES?}

No brief review can cover the extensive work now going on under the title social indicators, social accounting or quality of life. Only an example is offered from the author's own work (Andrews \& Withey, 1976) but it does illustrate some of the possible payoffs from quality of life research. The conceptual model proposes that a person's overall sense of life quality is understandable as a combination of evaluative responses to life "domains" (areas of activity). Over 100 items were used to measure a very wide variety of domains and several items were used to assess perceived overall life quality. These items were used in interviews with several representative samples of American adults. Based on these data the domain items were grouped (by correlational association) into a smaller number of semiindependent clusters. Thus, using smallest-spaceanalysis or cluster analysis one can develop a structural picture, like a tinker toy, of people's evaluations of life domains. This cluster structure was stable across 10 different subgroups of the adult population and were highly replicable in independent national samples. Analyses from more than one survey showed that 12 domains explained $50-60 \%$ of the variance in an index of overall life quality. Also, additive combinations of satisfaction in domains worked as well as more complicated models of combinatory rules.

What does this mean? Among other conclusions these findings indicate that components of family satisfaction tend to correlate (cluster); so do components of job satisfaction, income, standard of living and personal accomplishment tend to cluster, as do neighborhood variables and so forth. These data also show that family satisfaction is more important in overall evaluation than is job or neighborhood satisfaction. They also show that even though evaluations of, for instance, local commercial services are not terribly influential in overall evaluations they, as a cluster, do contribute something as do assessments in another cluster, the activity of the national government. This degree of consistent organization may be a bit surprising but it does provide a context for judging how changes in the physical and social environment may influence subjective judgments of well-being and quality of life. Some areas (domains) of life will contribute much more to people's sense of well being than others and the amount of contribution can be fairly consistently quantified.

If any aspect of quality of life is a component of program or policy evaluation this context and structure for people's subjective evaluation is important to know. Such a structure provides a forecast of the likely impact of improved satisfaction in some domain on overall improvements in judged quality of life. It certainly inhibits excessive optimism or discouragement. 


\section{WHAT DETERMINES SUBJECTIVE WELFARE?}

Assuming that cognitive judgments have some importance for peoples' behavior, for their feelings about themselves and their world and for others' attempts to improve conditions, what is the key to understanding subjective judgments? Human judgments tend to be relative. Relative to what? From the days of psychophysics judgment has been seen as occurring in a context in which some standard or range is used as a reference. If people are asked to judge a program to reduce highway accidents, program achieved accident figures are compared with pre-program rates. If the latter are higher there is some degree of satisfaction with the program depending on the size of the arithmetic difference. If researchers ask respondents how pleased or satisfied they are with various areas or activities in their lives, a statement of "fairly satisfied" means something, but more insight is gained if one knows the standard used for such a judgment. Even if there are troubles in quantification and measurement it is helpful to know something about the reference standard.

Campbell, Converse, and Rodgers (1976) have tried the model of aspirations. For most people achievement will not reach aspirations so satisfaction becomes a matter of the smallness of the discrepancy between present and aspired conditions. A similar model among policymakers is one that uses as a reference standard some minimal figure such as acceptable rate of unemployment. However, another model uses a minimal figure such as minimum wage or poverty level income and assumes that satisfaction increases as the discrepancy between income and standard gets larger.
Other models may deal with distributional reference standards. Above the mean or in the top $10 \%$ are evaluative judgments within this context. The relevant distribution may be an individual's history or experiences or it may be a distribution for a group. Parducci (1965) proposes the idea of a neutral judgment point that depends on the distribution of positive and negative outcomes. Specifically the reference point is proposed to fall halfway between the mid-point of the range of outcomes and the median outcome over a period of experience. It is hypothesized that this is a compromise between the extremes of experience and the pattern of actual or typical experiences. An implication of this model is that people will be more pleased with negatively skewed outcomes than positivcly skewed ones. In negatively skewed distributions over half of the outcomes will be above the "psychologically neutral point." Other models use ratio adaptation levels, and various multiple point references. Others could be invented.

Since quality of life research and evaluation research involves similar problems and issues it would seem that they might profitably contribute to each other. "Quality" implies "Evaluation" and standards for comparison, and pattern and quantity, and combination rules, and weighting, and aggregate and distributional outcomes, and extra-individual and intra-individual phenomena. The methodologies and the findings should be mutually valuable to both research orientations.

\section{REFERENCES}

ANDREWS, R., \& WITHEY, S. Social indicators of well-being. New York: Plenum, 1976.

BAUER, R. (Ed.). Social indicators. Cambridge, Mass.: MIT Press, 1966.

CAMPBELL, A., CONVERSE, P., \& RODGERS, W. The quality of American life. New York: Russell Sage, 1976.

DUNCAN, O. D. Does money buy satisfaction? Social Indicators Research, 1975, 2, 267-274.

EASTERLIN, R. A. Does money buy happiness? The Public Interest, 1973, 30, 3- 10 .
OLSON, M., JR. The plan and purpose of a social report. The Public Interest, Spring 1969, 15, 85-97.

PARDUCCI, A. Category judgment: A range-frequency model. Psychological Review, 1965, 72, 6, 407-418.

RAINWATER, L. What money buys. New York: Basic, 1974.

SHELDON, E. B., \& MOORE, W. E. (Eds.). Indicators of social change. New York: Russell Sage, 1968. 